\title{
Case report: increased single-nephron estimated glomerular filtration rate in an adult patient with low birth weight
}

Yuriko Shiozaki, Tomoyuki Fujikura* (D), Shinsuke Isobe, Ibuki Takatsuka, Taichi Sato, Daiki Goto, Sayaka Ishigaki, Naro Ohashi and Hideo Yasuda

\begin{abstract}
Background: Low birth weight (LBW) is associated with end-stage kidney disease and hypertension and is considered to be a surrogate marker of low nephron number. Low nephron number is hypothesized to contribute to glomerular hyperfiltration that may cause kidney injury; however, this is not yet proven. Until now, the hyperfiltration in LBW patients has not been shown directly yet.

Case presentation: A 23-years-old female was referred with the persistent proteinuria and decreased renal function (estimated glomerular filtration rate by cystatin $C\left(\right.$ (eGFR $\left.\left.\mathrm{cys}_{\mathrm{s}}\right) ; 41.86 \mathrm{ml} / \mathrm{min}\right)$. She was a premature baby with low birth weight (704 g, 24 gestational weeks). Renal biopsy demonstrated focal segmental glomerulosclerosis (FSGS) of the perihilar variant with expanded glomerular diameter. We calculated the single-nephron estimated glomerular filtration rate (SN-eGFR) that was higher than that of the same age group in the healthy living kidney donors and speculated that glomerular hyperfiltration is a pathophysiological cause of FSGS.

Conclusion: This is the first case of SN-eGFR measurement in a patient with LBW. The increased SN-eGFR in this case provides an important insight into the pathophysiological mechanisms of LBW for its progression to kidney disease.
\end{abstract}

Keywords: Low birth weight, Single-nephron estimated glomerular filtration rate, Glomerular hyperfiltration

\section{Background}

Low birth weight (LBW) is associated with end-stage kidney disease and hypertension [1,2], and it is a marker of poor fetal growth because of pre-term birth and/or intrauterine growth restriction. LBW is considered to correlate with reduced nephron number [3]. This reduced nephron number is hypothesized to contribute to the glomerular hyperfiltration, followed by kidney injury [4]. Focal segmental glomerulosclerosis (FSGS) patients who had a history of LBW were shown to have glomerulomegaly, high glomerular volumes, and low glomerular densities [5, 6], which supports the hyperfiltration hypothesis. However, until now, the hyperfiltration in LBW patients has not been shown directly yet.
Single-nephron glomerular filtration rate (SN-GFR) measurement has been proposed using healthy living kidney donors [7], which may provide us important insights into some glomerular diseases. Indeed, the measurement of SN-GFR is anticipated to elucidate the pathophysiological association between glomerular hyperfiltration and LBW [8].

We report a case of FSGS with a history of LBW in which the SN-eGFR is increased, suggestive of glomerular hyperfiltration. Our finding shows the need for a large number of longitudinal SN-GFR measurements in LBW patients to further understand the mechanism of FSGS.

\section{Case presentation}

A 23-years-old female was referred to our hospital following a complaint of persistent proteinuria. Proteinuria (1+) had been detected on routine examinations at the
* Correspondence: tfuji@hama-med.ac.jp
Hamamatsu University School of Medicine, Internal Medicine 1, 1-20-1 Handayama, East Ward, Hamamatsu, Shizuoka 431-3192, Japan
(C) The Author(s). 2020 Open Access This article is distributed under the terms of the Creative Commons Attribution 4.0 International License (http://creativecommons.org/licenses/by/4.0/), which permits unrestricted use, distribution, and reproduction in any medium, provided you give appropriate credit to the original author(s) and the source, provide a link to the Creative Commons license, and indicate if changes were made. The Creative Commons Public Domain Dedication waiver (http://creativecommons.org/publicdomain/zero/1.0/) applies to the data made available in this article, unless otherwise stated. 
age of 21 , and it has been getting worse in the last 2 years. $(1+\rightarrow 2+, 1.54 \mathrm{~g}$ of urinary protein in $24 \mathrm{~h})$. She was a premature baby with low birth weight $(704 \mathrm{~g}, 24$ gestational weeks). Her growth and development were normal. She has a family history of Werner syndrome on her mother's side. She had no medication and no history of pregnancy. Physical examination revealed the following: height, $150 \mathrm{~cm}$; weight, $41 \mathrm{~kg}$; body mass index, 17.9 $\mathrm{kg} / \mathrm{m}^{2}$; blood pressure, $120 / 58 \mathrm{mmHg}$; pulse rate, 65 beats $/ \mathrm{min}$; and temperature, $36^{\circ} \mathrm{C}$. She had no history of hypertension, her estimated daily salt intake was 5.0-6.0 g. She is not a vegetarian, and her estimated daily protein intake was $45.0 \mathrm{~g}$. There was no abnormality observed in other physical examinations.

Urinalysis revealed proteinuria (2+) but no hematuria. Her 24-h urinary protein, serum creatinine, and serum cystatin C levels were $1.08 \mathrm{~g}, 0.94 \mathrm{mg} / \mathrm{dL}$, and $1.39 \mathrm{mg} / \mathrm{L}$, respectively. Her serum albumin was $4.4 \mathrm{~g} / \mathrm{dl}$. Her eGFR with body surface area (BSA) adjustment was calculated: eGFR $_{\text {cys }}$ calculated using CKD-EPI (The Chronic Kidney Disease Epidemiology Collaboration) cystatin $\mathrm{C}$ equation, $55 \mathrm{ml} / \mathrm{min} / 1.73 \mathrm{~m}^{2}$ [9]; eGFR cr-cys $_{\text {calculated using }}$ the modified CKD-EPI creatinine- cystatin $C$ equation with the coefficient for Japanese $\left(0.908 \times\right.$ CKD-EPI cr-cys $\left._{\text {s }}\right)$ [10], $60 \mathrm{ml} / \mathrm{min} / 1.73 \mathrm{~m}^{2}$; and $\mathrm{eGFR}_{\mathrm{cr}}$ calculated using the equation for the Japanese population, $62 \mathrm{ml} / \mathrm{min} /$
$1.73 \mathrm{~m}^{2}$ [11]. Without BSA adjustment, individualized eGFR $\mathrm{cys}_{\text {cys }}, \mathrm{eGFR}_{\mathrm{cr}-\mathrm{cys}}$, and $\mathrm{eGFR}_{\mathrm{cr}}$ were $41.86 \mathrm{ml} / \mathrm{min}$, $45.61 \mathrm{ml} / \mathrm{min}$, and $47.19 \mathrm{ml} / \mathrm{min}$, respectively (Table 1 ). Creatinine clearance was $47.87 \mathrm{ml} / \mathrm{min}$. On ultrasound, the longitudinal diameters of her kidneys were $9.9 \mathrm{~cm}$ for the right kidney and $9.2 \mathrm{~cm}$ for the left kidney.

A percutaneous renal biopsy was performed to establish the diagnosis. On microscopy, the specimen contained 15 glomeruli. Three glomeruli were globally sclerotic, which showed a solidification pattern. Two glomeruli had segmental sclerosis of the perihilar variant with a hyalinosis. The mean of glomerular diameter of 15 glomeruli was $233 \mu \mathrm{m}$ (Fig. 1). Electron microscopy revealed minimal foot process effacement and no electron-dense deposits (Fig. 1).

We calculated the single-nephron estimated glomerular filtration rate (SN-eGFR) using the following method. Using contrast computed tomography (CT) angiograms, the patient's kidneys were three-dimensionally reconstructed, and total renal cortical volume was estimated using SYNAPSE VINCENT (FUJIFILM, Japan). Glomerular area $\left(\mathrm{mm}^{2}\right)$, glomerular volume $\left(\times 10^{6} \mu \mathrm{m}^{3}\right)$, and glomerular density $\left(/ \mathrm{mm}^{3}\right)$ were measured using the method reported by Denic et al. [12] (Fig. 1 a). Considering that the biopsy specimen had two segmentally sclerotic glomeruli, we included them into the non-sclerotic

Table 1 Detailed morphometric characteristics and comparison with the other two studies

\begin{tabular}{|c|c|c|c|}
\hline Characteristics & This study & Living kidney donors (93-94\% Caucasian) & Living kidney donors (100\% Japanese) $^{* * *}$ \\
\hline \multicolumn{4}{|l|}{ Kidney function } \\
\hline $\mathrm{eGFR}_{\text {cys }}(\mathrm{ml} / \mathrm{min})$ & 41.86 & \multirow[t]{3}{*}{ Total GFR: $127 \pm 25 \mathrm{ml} / \mathrm{min}^{*}$} & \multirow[t]{3}{*}{$\mathrm{eGFR}_{\mathrm{cr}}: 76 \pm 12 \mathrm{~mL} / \mathrm{min} / 1.73 \mathrm{~m}^{2}$} \\
\hline $\mathrm{eGFR}_{\text {cr-cys }}(\mathrm{ml} / \mathrm{min})$ & 45.61 & & \\
\hline $\mathrm{eGFR}_{\mathrm{cr}}(\mathrm{ml} / \mathrm{min})$ & 47.19 & & \\
\hline \multicolumn{4}{|l|}{ Morphometric measurements } \\
\hline Renal parenchymal volume per kidney $\left(\mathrm{cm}^{3}\right)$ & 90.15 & & $124 \pm 24$ \\
\hline Renal cortical volume per kidney $\left(\mathrm{cm}^{3}\right)$ & 69.25 & & $89 \pm 19$ \\
\hline Cortical area in biopsy specimen $\left(\mathrm{mm}^{2}\right)$ & 8.62 & & $2.96 \pm 0.79$ \\
\hline Glomerular volume $\left(\times 10^{6} \mu^{3}\right)$ & 7.16 & & $2.44 \pm 1.04$ \\
\hline Glomerular density $\left(/ \mathrm{mm}^{3}\right)$ & 1.33 & & $2.42 \pm 0.67$ \\
\hline Non-sclerotic nephron number per kidney & 208,000 & & $650,000 \pm 220,000$ \\
\hline \% Globally sclerotic glomeruli & $20 \%$ & $1.1(0.8-1.5)^{* *}$ & $4.7(0-35.3)$ \\
\hline Total nephron number per kidney & 265,000 & $970,000 \pm 430,000^{*}$ & $710,000 \pm 220,000$ \\
\hline \multicolumn{4}{|l|}{ Calculated nephron-related values } \\
\hline Single-nephron eGFR $\mathrm{cys}_{\text {(n) }}$ (nl/min) & 101 & \multirow{3}{*}{$\begin{array}{l}\text { Single-Nephron GFR: } \\
79 \pm 42 \mathrm{nl} / \mathrm{min}^{*}\end{array}$} & \\
\hline Single-nephron eGFR $\mathrm{cr-cys}_{\mathrm{s}}(\mathrm{nl} / \mathrm{min})$ & 110 & & \\
\hline Single-nephron eGFR $\mathrm{cr}(\mathrm{n} \mid / \mathrm{min})$ & 113 & & \\
\hline \multicolumn{4}{|c|}{  } \\
\hline
\end{tabular}




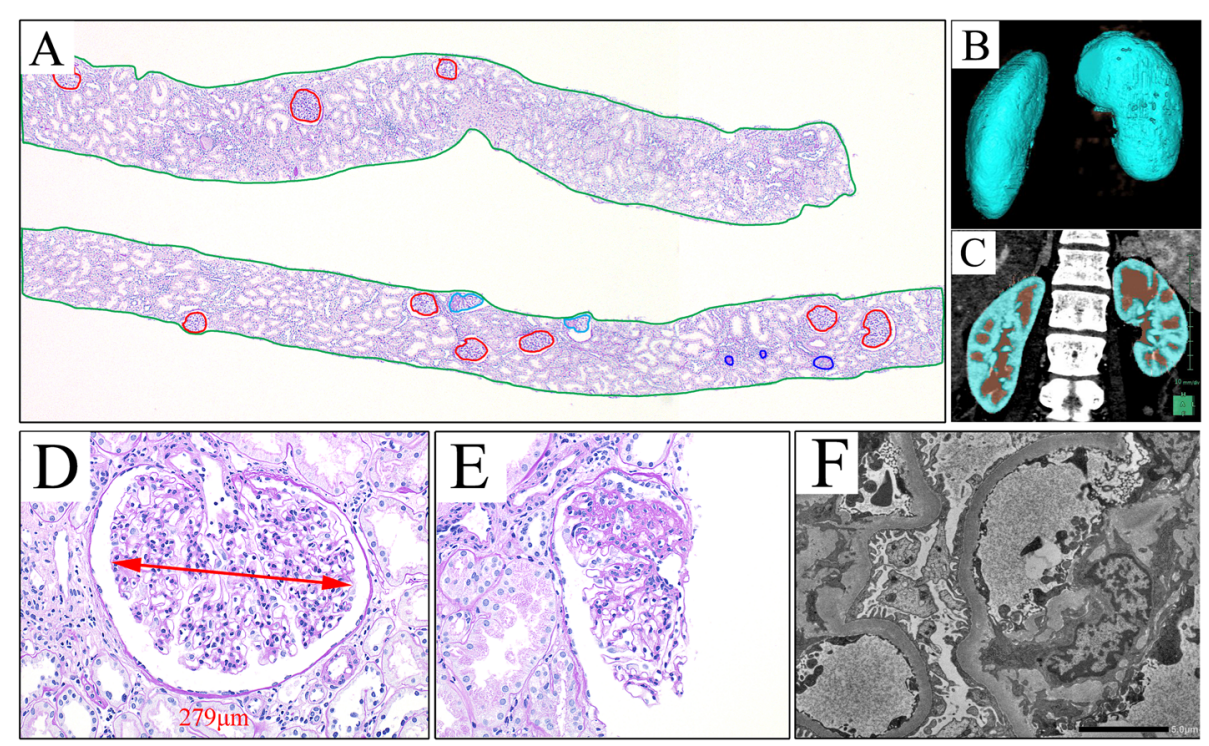

Fig. 1 Kidney biopsy morphometry and computed tomography (CT) scan with contrast. a The non-sclerotic glomerular (red outline), partial nonsclerotic glomerular (cyan outline, counted as 0.5 glomerulus), and total glomerular areas (both red, cyan, and blue outlines) were measured. The glomerular volume and density were measured from the area of the glomeruli and the area of the cortex (green outline). $\mathbf{b}$ A three-dimensional image was reconstructed to determine the cortical volume. c The enhanced area in the coronal plane of the CT scan was semiautomatically colored. $\mathbf{d}$, e Representative glomeruli are shown. Segmental sclerosis at perihilar location is noted (e). $\mathbf{f}$ Electron microscopy reveals minimal foot process effacement

glomerular number. The total glomerular number and non-sclerotic glomerular number per kidney were calculated by multiplying the total cortical volume $\left(\mathrm{mm}^{3}\right)$ by the glomerular density $\left(/ \mathrm{mm}^{3}\right)$, and dividing by 2 (per kidney), dividing by 1.43 (tissue volume shrinkage due to paraffin embedding), dividing by 1.268 (volume shrinkage due to loss of tissue perfusion pressure), and rounded to the nearest 10,000 nephrons [12]. The percentage of global glomerulosclerosis was calculated by dividing the globally sclerotic glomeruli by the total glomerular number (Table 1). The SN-eGFR was calculated as the individualized eGFR divided by the total nephron number for both kidneys and rounded to the nearest $1 \mathrm{nl} / \mathrm{min}$ [7]. We found out that her SN-eGFR was higher than that of the same age group $(79 \pm 42 \mathrm{nl} / \mathrm{min})$ [7] (Table 1).

After the diagnosis, angiotensin receptor blocker (losartan $50 \mathrm{mg}$ ) was administered. At follow-up 6 months later, the 24-h urinary protein decreased slightly $(0.87 \mathrm{~g})$ without alterations in serum creatinine $(0.91 \mathrm{mg} / \mathrm{dl})$.

\section{Discussion and conclusions}

We report an adult case of FSGS with LBW and demonstrate a higher SN-eGFR than that of the age-matched healthy living kidney donors [7] (Table 1). Increased SNeGFR could indicate glomerular hyperfiltration, which contributes to the pathophysiology of FSGS.

Glomerular hyperfiltration caused by low nephron number is hypothesized to be the pathophysiology of kidney diseases. In fact, some epidemiologic studies have shown the association between LBW and comorbidities of kidney diseases in childhood [14] or adolescence [15]. In Helsinki Birth Cohort Study, LBW and prematurity were shown to be associated with increased risk for the development of chronic kidney disease in adulthood [16]. Using the two-dimensional areal density of the glomeruli calculated using the kidney biopsy specimens, LBW-FSGS children had lower glomerular density and larger glomerular volume than the normal-birth-weight FSGS children and exhibited the histopathological and clinical findings that were consistent with secondary FSGS (e.g. perihilar variant, mild proteinuria) [5]. These studies support the pathophysiology of glomerular hyperfiltration that is associated with LBW.

Recently, using both CT angiography and kidney biopsy specimen, the novel methods for estimating the total nephron number in living humans have been proposed [12, 13]. Furthermore, combining this estimation of the total nephron number and measurement of GFR, Denic et al. showed the measurement of SN-GFR in healthy living kidney donors [7]. Using this same technique with eGFR, we estimated the SN-eGFR in this case, which was higher than that of the same age group in the healthy living kidney donors (93.7\% Caucasian) [7] (Table 1). Some biases on the measurement of total nephron number or eGFR can prevent us from the accurate interpretation of SN-eGFR. From several human population studies, the average nephron number varies 
up to 13-fold, and the mean glomerular volume varies up to 7-fold [17]; hence, the genetic difference between the healthy living kidney donors (93.7\% Caucasian) [7] and a Japanese patient could influence the nephron number. However, the estimated total nephron number in this case is much lower than the Japanese living kidney donors $(265,000$ vs. $710,000 \pm 220,000$ per kidney) [13] (Table 1). Since we did not use an accurate GFR measurement such as inulin clearance, the inaccuracy of estimating eGFR may mislead the measurement of SNeGFR. Yet, the two equations used to estimate eGFR $\left(e G_{\text {cys }}\right.$ and $\left.e G F R_{\text {cr-cys }}\right)$ here are based on CKD-EPI study [9] and are developed to establish a more diagnostic accuracy in the Japanese population [11], and both results are significantly associated with each other. Accordingly, we consider that the estimated SN-eGFR in this case is reliable and considerably high.

Occasionally, glomerular hyperfiltration is a compensatory mechanism, such as in age-related nephrosclerosis [12] or hypertension-related nephrosclerosis, of an acquired nephron loss. The ratio of globally sclerotic glomeruli in this case $(20 \%)$ is higher than those of healthy living kidney donors (Table 1) $[12,13]$, and they showed the "solidification" pattern of global sclerosis, and the patient in this case has no history of hypertension. This means her glomerular hyperfiltration is not a result of acquired nephron loss but a result of congenitally low nephron number, which might be associated with LBW. It is certainly unclear whether this glomerular hyperfiltration is indeed pathophysiological cause of FSGS. In general, kidney donors lost about half of the nephrons after the donation, followed by glomerular enlargement with increased SN-GFR as a compensatory mechanism. Nevertheless, kidney donation itself rarely leads to progressive kidney disease. However, in this case, the biopsy findings revealed some segmental sclerotic glomeruli of the perihilar variant and glomerulomegaly, which is consistent with the predominant findings observed in LBWFSGS patients [6] and obesity-related FSGS patients [18]. Therefore, we consider that the glomerular hyperfiltration experienced in this case could be the pathophysiological cause of FSGS, although its detailed pathophysiological mechanism is not yet proven.

Although this case study can directly show neither the association between glomerular hyperfiltration and LBW nor the pathophysiology of glomerular hyperfiltration, this study could provide an important insight into the pathophysiological mechanisms of LBW for its progression to kidney disease. To specifically elucidate the pathophysiology of glomerular hyperfiltration, large and longitudinal studies are required. Additionally, instead of performing a kidney biopsy that is an invasive procedure, the development of non-invasive procedures to estimate nephron number [19] may hasten the elucidation of this mechanism.

\section{Abbreviations}

CKD-EPI: The Chronic Kidney Disease Epidemiology Collaboration;

FSGS: Focal segmental glomerulosclerosis; LBW: Low birth weight; SNeGFR: Single-nephron estimated glomerular filtration rate; SN-GFR: Singlenephron glomerular filtration rate

\section{Acknowledgments}

None.

\section{Authors' contributions}

YS, TF, SI, IT, TS, NO and HY treated the patient. YS, TF, SI, IT, TS, DG, SI, NO and $\mathrm{HY}$ performed the histopathological analysis of the kidney biopsy. SI calculated the total glomerular number. YS, TF and HY wrote the manuscript. All authors have read and approved the manuscript.

\section{Funding}

None.

Availability of data and materials

All the data relevant to this report are included in the manuscript.

Ethics approval and consent to participate

None.

\section{Consent for publication}

The patient gave written informed consent to use all the personal data and the images of the kidney biopsy. The patient gave written informed consent for publication of this report and the associated images.

\section{Competing interests}

The authors declare that they have no competing interests.

Received: 4 September 2019 Accepted: 17 February 2020

Published online: 04 March 2020

\section{References}

1. Luyckx VA, Brenner BM. Birth weight, malnutrition and kidney- associated outcomes-a global concern. Nat Rev Nephrol. 2015;11:135-49.

2. Vikse BE, Irgens LM, Leivestad T, Hallan S, Iversen BM. Low birth weight increases risk for end-stage renal disease. J Am Soc Nephrol. 2008;19:151-7.

3. Hughson M, Farris AB, Douglas-Denton R, Hoy WE, Bertram JF. Glomerular number and size in autopsy kidneys: the relationship to birth weight. Kidney Int. 2003;63:2113-22.

4. Brenner BM, Garcia DL, Anderson S. Glomeruli and blood pressure. Less of one, more the other? Am. J. Hypertens. 1988;1:335-47.

5. Koike K, Ikezumi Y, Tsuboi N, Kanzaki G, Haruhara K, Okabayashi Y, et al. Glomerular density and volume in renal biopsy specimens of children with proteinuria relative to preterm birth and gestational age. Clin J Am Soc Nephrol. 2017;12:585-90

6. Hodgin JB, Rasoulpour M, Markowitz GS, D'Agati VD. Very low birth weight is a risk factor for secondary focal segmental glomerulosclerosis. Clin J Am Soc Nephrol. 2009:4:71-6.

7. Denic A, Mathew J, Lerman LO, Lieske JC, Larson JJ, Alexander MP, et al. Single-nephron glomerular filtration rate in healthy adults. N Engl J Med. 2017:376:2349-57.

8. Rosenberg ME, Hostetter TH. Single-nephron glomerular filtration rate in healthy adults. N Engl J Med. 2017;377:1202-3.

9. Inker LA, Schmid CH, Tighiouart H, Eckfeldt JH, Feldman HI, Greene T, et al. Estimating glomerular filtration rate from serum Creatinine and Cystatin C. N Engl J Med. 2012;367:20-9.

10. Matsuo S, Imai E, Horio M, Yasuda Y, Tomita K, Nitta K, et al. Revised equations for estimated GFR from serum Creatinine in Japan. Am J Kidney Dis. 2009:53:982-92

11. Horio M, Imai E, Yasuda Y, Watanabe T, Matsuo S, Collaborators developing the Japanese equation for estimated GFR. GFR estimation using standardized serum cystatin C in Japan. Am J Kidney Dis. 2013:61:197-203.

12. Denic A, Lieske JC, Chakkera HA, Poggio ED, Alexander MP, Singh P, et al. The substantial loss of nephrons in healthy human kidneys with aging. J Am Soc Nephrol. 2017;28:313-20.

13. Sasaki T. Biopsy-based estimation of total nephron number in Japanese living kidney donors. Clin Exp Nephrol. 2019;23:629-37. 
14. Shinzawa M, Tanaka S, Tokumasu H, Takada D, Tsukamoto T, Yanagita M, et al. Association of low Birth Weight with Childhood Proteinuria at age 3 years: a population-based retrospective cohort study. Am J Kidney Dis. 2019; 74:141-3.

15. Khalsa DDK, Beydoun HA, Carmody JB. Prevalence of chronic kidney disease risk factors among low birth weight adolescents. Pediatr Nephrol. 2016;31: 1509-16.

16. Eriksson JG, Salonen MK, Kajantie E, Osmond C. Prenatal growth and CKD in older adults: longitudinal findings from the Helsinki birth cohort study, 1924-1944. Am J Kidney Dis. 2018;71:20-6.

17. Puelles VG, Hoy WE, Hughson MD, Diouf B, Douglas-Denton RN, Bertram JF. Glomerular number and size variability and risk for kidney disease. Curr Opin Nephrol Hypertens. 2011;20:7-15.

18. Kambham N, Markowitz GS, Valeri AM, Lin J, D'Agati VD. Obesity-related glomerulopathy: an emerging epidemic. Kidney Int. 2001;59:1498-509.

19. Brennan S, Kandasamy Y. Ultrasound imaging of the renal parenchyma of premature neonates for the assessment of renal growth and Glomerulomegaly. Ultrasound Med Biol. 2017;43:2546-9.

\section{Publisher's Note}

Springer Nature remains neutral with regard to jurisdictional claims in published maps and institutional affiliations.

Ready to submit your research? Choose BMC and benefit from:

- fast, convenient online submission

- thorough peer review by experienced researchers in your field

- rapid publication on acceptance

- support for research data, including large and complex data types

- gold Open Access which fosters wider collaboration and increased citations

- maximum visibility for your research: over $100 \mathrm{M}$ website views per year

At BMC, research is always in progress.

Learn more biomedcentral.com/submissions 